\title{
La espiritualidad como estrategia para resignificar la violencia feminicida en madres de víctimas
}

\section{Spirituality as a Strategy for Victims' Mothers to Resignify Feminicidal Violence}

Eleane Proo Méndez ${ }^{*}$

Karina Bárcenas Barajas²

${ }^{1 *}$ Estudiante de doctorado, Facultad de Ciencias Políticas y Sociales, Universidad Nacional Autónoma de México (FCPS-UnAM), Ciudad de México, México. email: eleaneproo@politicas.unam.mx, Ohttps://orcid.org/oooo-0oo3-0641-8718

${ }^{2}$ Investigadora en el Instituto de Investigaciones Sociales, Universidad Nacional Autónoma de México (IIS-UnAm), Ciudad de México, México. email: kb.barcenas@sociales.unam.mx, Ohttps://orcid.org/oooo-0oo2-4741-6199

*Autora para correspondencia

Recibido: 18 de julio 2020 Aceptado: 26 de abril de 2021

Publicado: o7 de junio de 2021

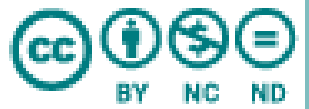

Esta obra está protegida bajo una Licencia Creative Commons Atribución-NoComercialSinDerivadas 4.0 Internacional (CC BY-NC-ND 4.0)

\section{Resumen}

En México, el movimiento feminista ha luchado por la erradicación de la violencia feminicida, una expresión sistemática de odio que atenta en contra de la vida de las mujeres y las niñas. A partir de una metodología cualitativa, que se enfoca en la experiencia subjetiva de cinco madres de víctimas, este artículo problematiza la configuración de la espiritualidad como estrategia de subjetivación e individualización de las creencias. A su vez, la espiritualidad

CÓMO GITAR: Proo, Eleane y Bárcenas, Karina. (2021). La espiritualidad como estrategia para resignificar la violencia feminicida en madres de víctimas. Revista Interdisciplinaria de Estudios de Género de El Colegio de México, \%, e678. doi: http://dx.doi.org/10.24201/reg.v7i1.678 
funge como una herramienta política que sustenta la exigencia de acceso a la justicia, contribuye al bienestar mental y surge, además, como mediación entre la subjetividad y el problema estructural que representan la impunidad e injusticia en el país.

Palabras clave: violencia de género; movimiento feminista; espiritualidad; creencias religiosas personales.

\begin{abstract}
The feminist movement in Mexico has fought to stamp out feminicidal violence, defined as a systematic expression of hatred that threatens the lives of women and girls. Based on a qualitative methodology focused on the subjective experience of five mothers of victims, this article problematizes spirituality as a means of subjectivizing and individualize beliefs. This strategy is also a political tool that supports access to justice, improves mental wellbeing, and mediates between subjectivity and Mexico's structural problem of impunity and injustice.
\end{abstract} Keywords: gender violence; feminist movement; spirituality; personal religious beliefs.

\title{
Introducción
}

La violencia feminicida ${ }^{1}$ es la expresión máxima de violencia contra las mujeres y en México es un fenómeno que va en aumento desde hace más de 25 años. Los feminicidios, que atentan en contra de la vida de las mujeres, también vulneran la existencia de otras y otros: las hijas, los hijos y las madres de las víctimas. Es precisamente en ellas - las madres - en quienes se encuadra la mirada para analizar de qué manera la espiritualidad se convierte en una estrategia para resignificar este tipo de violencia y clamar por el acceso a la justicia que les ha sido negado por parte del Estado.

\footnotetext{
${ }^{1}$ Este concepto deviene del término femicidio, utilizado en 1992 por Diana Rusell y Jill Radford en su libro Femicide: The Politics of Woman Killing, para denotar los asesinatos de mujeres con violencia extrema (Atencio, 2011). En 2006, dicho texto fue traducido al español por Marcela Lagarde y esto permitió la transformación del concepto a feminicidio, que pone el énfasis en la impunidad y responsabilidad del Estado bajo las que ocurren estos asesinatos (Proo, 2018).
} 
Después de enfrentar un acontecimiento como el feminicidio de una hija — con actos de violencia extrema y como consecuencia de una estructura patriarcal, que entra en crisis frente a la autonomía de las mujeres para decidir sobre su vida y sobre su cuerpo ${ }^{2}$-, las madres adquieren conciencia sobre la magnitud y las implicaciones de una violencia de gran arraigo como ésta. En paralelo con la resignificación de dicho crimen, por medio de algunas prácticas espirituales, sus vidas toman nuevos rumbos: se convierten en actores sociales relevantes gracias al activismo-, o bien, deciden acompañar a otras mujeres víctimas de violencia de género.

En este artículo las identidades de las madres de víctimas de la violencia feminicida permiten problematizar de qué manera se encuentran dos caras de la institucionalización de un sistema de creencias: la religión y la espiritualidad, con un orden de género.

Por una parte, las religiones han jugado un rol central en la construcción y legitimación de una estructura patriarcal por medio de sus símbolos culturales, sus conceptos normativos, sus instituciones y organizaciones sociales, elementos que, siguiendo a Scott (1996), son constitutivos de las relaciones sociales basadas en las diferencias que distinguen los sexos, por lo que generan desigualdades estructurales que a su vez son causantes de la violencia feminicida. Por otro lado, la espiritualidad, entendida como un "campo abierto de significados atribuidos a lo sagrado" (Pace, 2011, p. 30) visibiliza una forma contemporánea y creciente de religiosidad para enfatizar tanto la experiencia religiosa subjetiva, como la actitud frente a la fuente legítima de autoridad religiosa que prescinde o limita el rol de las instituciones o grupos religiosos tradicionales (Frigerio, 2016).

Aun cuando existen casos en los que desde el interior de los espacios religiosos se deconstruyen los mandatos de género, lo que lleva a la producción de otras formas de religiosidad (véase Villalobos Nájera, 2016; Espino Armendáriz, 2019; Mazariegos Herrera, 2019; Bárcenas Barajas, 2020), en el caso de las madres de víctimas es la espiritualidad cristiana ${ }^{3}$ la que se

\footnotetext{
${ }^{2}$ Un análisis acerca del derecho a decidir sobre el propio cuerpo desde una perspectiva que trasciende la interrupción legal del embarazo se encuentra en Bárcenas Barajas (2021).

${ }^{3}$ Como se detalla más adelante, se parte de la distinción de Houtman y Aupers (2007) entre lo que denominan una espiritualidad cristiana y una espiritualidad postcrisiana.
} 
convierte en una alternativa para resignificar la violencia feminicida. Estas mujeres retoman una matriz de sentido que aprendieron como parte de su religión de origen y al mismo tiempo cuestionan la herencia patriarcal que las religiones han impuesto por medio de su visión del mundo. Es desde su experiencia subjetiva, sin mediación de alguna autoridad religiosa o vínculo comunitario que invocan la existencia de un ser trascendente para, de inicio, dotar de sentido un acontecimiento trágico como éste, y posteriormente implorar por la justicia que les ha sido negada, pero que continúan buscando en las dimensiones terrenales.

En ambos momentos la espiritualidad posee un impacto positivo en el bienestar mental y subjetivo. Las relaciones entre religiosidad y salud mental son de larga data, primeramente, por medio de la filosofía, pasando por la psicología hasta llegar a la neurociencia. Para Carlos Valiente-Barroso (2013) la filosofía aportó las bases para el estudio psicológico de la experiencia espiritual y la religiosidad asociado con la salud y el bienestar. Desde su perspectiva, "la relación entre espiritualidad y psicología hunde sus raíces históricas en la propia denominación conceptual de esta disciplina, que, etimológicamente, significa 'ciencia del alma"” (Valiente-Barroso, 2013, p. 68).

Desde una mirada contemporánea, Ana Salgado (2014) presenta un panorama sobre la manera en que este tema se ha explorado desde la década de 1970. Concretamente, en investigaciones relacionadas con mujeres, se puede mencionar la llevada a cabo por Yesica Puentes, Sandra Urrego y Ricardo Sánchez (2015), quienes en su pesquisa exploraron “el lugar de la espiritualidad y la religiosidad en la manera como un grupo de mujeres con cáncer de mama asumen, significan y enfrentan su enfermedad" (p. 481).

En relación con la salud mental y la vivencia subjetiva del duelo, Antillón y González (2018) establecen una crítica a los discursos disciplinarios y normativos de la psicología clínica que prescriben un "duelo normal" con un adecuado proceso de subjetivación de la pérdida, independientemente de cualquier circunstancia en que ésta haya sucedido. Dicha domesticación del potencial político del duelo también limita las posibilidades comunitarias, simbólicas y rituales para procesar el crimen cometido contra un ser querido. Ello lleva a reconocer la importancia de la espiritualidad como una estrategia que retoma un conjunto de matrices de 
sentido que se configuran socioculturalmente, pero que subjetivamente permiten resignificar la vivencia personal del duelo a causa de la violencia feminicida.

Recientemente, la sociología de la religión también se interesó en las relaciones que se establecen entre la espiritualidad y la salud en temas como: el uso de las terapias alternativas en los sistemas médicos (Toniol, 2015) y las estrategias de rehabilitación por el uso de estupefacientes (Odgers y Olivas, 2018). Asimismo, existe una línea de estudios que aborda el potencial político de la espiritualidad, en relación con las luchas por la justicia y la liberación de cualquier forma de violencia, dominación u opresión (véase Maher, 2015; hooks, 2017; Ramírez Morales, 2019). Es precisamente en esta perspectiva en la que se enmarca este artículo que revela el potencial político de una espiritualidad cristiana desde la subjetivación de la experiencia del duelo.

Debido a que no existen antecedentes o estudios previos sobre el tema que aquí se presenta, esta aproximación constituye un aporte para una agenda de investigación en la que convergen la sociología de la religión y los estudios de género. Esta perspectiva interdisciplinaria abre la posibilidad para indagar en las prácticas y los sentidos que se generan en el cruce de la violencia, el género, la espiritualidad y la salud mental, específicamente, en relación con la vivencia personal del duelo.

Partiendo de que para Antillón y González (2018) las "políticas del duelo" son las condiciones sociales de reconocimiento o negación de la pérdida, en este artículo se plantea que la espiritualidad cristiana constituye una política del duelo que permite la resignificación de la pérdida de una hija. En una situación de violencia tan traumática como el feminicidio, la pérdida se coloca como una estrategia política y de resistencia frente a la impunidad que viven las madres en su búsqueda de justicia.

Para cumplir con tal propósito, inicialmente se destacan tres ámbitos de lucha del activismo feminista para erradicar la violencia feminicida, se señala que esta lucha toma como punto de partida la movilización ciudadana encabezada, principalmente, por las madres de las víctimas. El andamiaje teórico-metodológico se sustenta en principios de la fenomenología sociológica y 
el interaccionismo simbólico, los cuales profundizan en el carácter simbólico de la vida social, así como en la indagación del mundo conocido y la experiencia subjetiva de las mujeres entrevistadas. Asimismo, el uso de la Teoría Fundamentada para la interpretación de los datos permite dilucidar los procesos de resignificación que posibilitan la espiritualidad cristiana y la individualización de las creencias en torno a dicho fenómeno.

De esta manera, el análisis conduce hacia las matrices de sentido religioso que hacen posible la configuración de una espiritualidad cristiana que expresa un potencial político tanto para resignificar la violencia feminicida, como para mantener la esperanza en una justicia divina, en tanto que las madres continúan con la exigencia para que el Estado garantice el acceso a la justicia terrenal por los crímenes cometidos contra la vida de sus hijas.

\section{El activismo feminista contra la violencia feminicida en México}

A lo largo de las últimas décadas el movimiento feminista ha cobrado gran relevancia en la generación de estrategias de resistencia contra la violencia feminicida en México, así como en la exigencia de acceso a la justicia y reparación del daño para las familias de las víctimas. En este sentido, la acción colectiva feminista ha sido clave en tres ámbitos de la lucha por la erradicación de este tipo de violencia: 1) la movilización ciudadana encabezada principalmente por las madres de las víctimas, 2) la disputa por nombrar el feminicidio en la ley, 3) los movimientos tecnopolíticos surgidos desde las redes sociodigitales.

En el caso de las agrupaciones organizadas y movilizadas por madres, primordialmente, así como familiares de víctimas, Ortega y Miller (2017) rescatan la existencia de Bordamos Feminicidios ${ }^{4}$ y Nuestras Hijas de Regreso a Casa como ejemplos de respuesta ante la ineficacia e impunidad del gobierno mexicano en la atención de mujeres desaparecidas y asesinadas por motivos de género. Asimismo, los autores ponen de manifiesto la importancia política que tuvo la colocación de las cruces rosas — hoy, emblema de las manifestaciones contra la violencia

\footnotetext{
${ }^{4}$ Para Ortega y Miller (2017) esta organización, dedicada a bordar en colectivo para mantener viva la memoria de las víctimas de feminicidio, cobra relevancia política por la promoción y fortalecimiento de redes de solidaridad cívica, así como por la creación de comunidades ciudadanas en contra de este tipo de violencia contra las mujeres (p. 254).
} 
feminicida - por parte de las madres de víctimas de feminicidio, en Ciudad Juárez, como estrategia para exigir acceso a la justicia y mantener visibilidad en el espacio público.

Las organizaciones de madres, familiares, amigos y aliados que luchan desde el activismo contra los feminicidios en diversas partes de México han tenido que enfrentar el acoso, la violencia e incluso la muerte. Tal fue el caso de Marisela Escobedo Ruiz, quien fue asesinada en 2010 mientras exigía justicia frente al Palacio de Gobierno de la ciudad de Chihuahua, por el feminicidio de su hija, Rubí Marisol Frayre Escobedo, perpetrado en 2008 (Ortega y Miller, 2017, p. 253).

Destaca que, pese a la visibilidad mediática que han logrado otras madres activistas, como Irinea Buendía, Aracely Osorio, Yesenia Zamudio y Lorena Gutiérrez, por mencionar algunas, el acceso a la justicia en los feminicidios de sus hijas - Mariana Lima Buendía, Lesvy Berlín Osorio, María de Jesús Jaimes Zamudio y Fátima Varinia Quintana Gutiérrez, respectivamente - ha sido escaso y deficiente. Sin embargo, junto con otras madres, han conformado no sólo redes de acompañamiento y denuncia colectiva, sino que han logrado cambios significativos en cuanto a la reclasificación y reconocimiento de la violencia feminicida por parte de las autoridades que han investigado sus casos.

En este sentido, en el ámbito legislativo, Marcela Lagarde, quien fungió como diputada federal entre 2003 y 2006, impulsó en conjunto con diputadas feministas, activistas y académicas la tipificación de la violencia feminicida y la creación de la Ley General de Acceso de las Mujeres a una Vida Libre de Violencia (LgAmvLV) por medio de la Comisión Especial de Feminicidio (liderada por Lagarde). La antropóloga narra el complejo proceso que significó la lucha por nombrar en la ley este tipo de violencia:

Tipificar este delito fue una acrobacia, porque ni siquiera estaba en la conciencia, ni siquiera estaba en las mentalidades; en México sólo tenemos una ley para la violencia intrafamiliar, y yo fui parte de las feministas que hace 20 años luchamos por una ley para erradicar la violencia contra las mujeres (Lagarde, 2006, p. 220). 
Y es que, a raíz de los asesinatos violentos y sistemáticos de mujeres por motivos de género ocurridos en Ciudad Juárez, Chihuahua, durante los años noventa, el uso del término feminicidio comenzaba a resonar mediáticamente, sumado a la demanda contra el gobierno mexicano por el caso "González y otras" (Campo Algodonero), aceptada por la Comisión Interamericana de Derechos Humanos en 2007. Ese mismo año, se publicó la LGAMVLV, donde la violencia feminicida se nombró y definió por primera vez. Lagarde amplía esta definición y la describe como:

[...] la forma extrema de violencia de género contra las mujeres, producto de la violación de sus derechos humanos en los ámbitos público y privado, está conformada por el conjunto de conductas misóginas - maltrato y violencia física, psicológica, sexual, educativa, laboral, económica, patrimonial, familiar, comunitaria, institucional - que conllevan impunidad social y del Estado y, al colocar a las mujeres en riesgo e indefensión, pueden culminar en el homicidio o su tentativa, es decir en feminicidio, y en otras formas de muerte violenta de las niñas y las mujeres: por accidentes, suicidios y muertes evitables derivadas de, la inseguridad, la desatención y la exclusión del desarrollo y la democracia (Lagarde, 2008, p. 237).

No obstante, aun con el logro del reconocimiento legislativo de la violencia feminicida como un problema sistemático, Álvarez (2020) recuerda que los procedimientos institucionales para el acceso a la justicia, en dichos casos parecen estancados y esto se refleja en el alto nivel de casos que quedan impunes en México ${ }^{5}$.

Por otro lado, Rovira (2018) afirma que los espacios del activismo feminista se han visto también permeados y potencializados por las redes sociodigitales, que permiten no sólo la interacción, sino una forma de organización colectiva con efectos en "los juzgados, las calles, las escuelas" y con contagio transnacional como un "proceso de toma de la palabra”. Asimismo,

\footnotetext{
5 Álvarez (2020) señala también la importancia que el movimiento feminista ha tenido para la acción y demanda colectiva por la exigencia de atención hacia todos los tipos de violencia ejercidos contra las mujeres, encabezado en los últimos años, en gran medida, por jóvenes que se han visto interpeladas por la violencia de género en su cotidianeidad.
} 
aunado a los activismos ya descritos, la aparición de hashtags como \#SiMeMatan ${ }^{6}$, \#VivasNosQueremos y \#NiUnaMenos (con origen en Argentina, 2015) han agregado participación y visibilidad de la lucha feminista en contra de la violencia feminicida.

En este breve recorrido acerca de los tres ámbitos donde el movimiento feminista ha sido clave para la lucha en contra de la violencia feminicida en México, destaca su función como transformador de la realidad social, con una "[...] fuerte influencia en distintos planos del propio ámbito político, además del social y cultural” (Álvarez, 2020, p.156).

\section{La espiritualidad cristiana y la individualización de las creencias}

La sociología y la antropología de la religión han desarrollado diversos acercamientos que permiten dar cuenta de los procesos de desinstitucionalización, subjetivación e individualización de las creencias, como el que aquí se analiza, a partir de lo que se conoce como modelos inclusivistas, los cuales "buscan descubrir las nuevas formas que adopta lo sagrado - y por ende lo religioso- en la sociedad secular" (De la Torre, 2013, p. 2). Como parte de estos modelos se encuentra la religiosidad, la mística y la espiritualidad.

Mientras esta última alude exclusivamente a la individualización de la experiencia religiosa, la religiosidad permite rastrear sus soportes y reanclajes simbólicos colectivos, sin desatender los efectos de su subjetivación (De la Torre, 2013). Por su parte, la dimensión mística, aun cuando va más allá de los límites impuestos por la religión y se sitúa en las coordenadas de la espiritualidad, implica eventos intangibles y entes sobrenaturales, en general de índole sagrada, que inspiran profunda veneración (Salles y Valenzuela, 1997).

Debido a que las experiencias de las madres de víctimas de feminicidio revelan una relación con Dios - que se construye desde su experiencia subjetiva, sin mediación de alguna autoridad religiosa o vínculo comunitario, y en lugar de responder a una práctica de veneración se compone de procesos de comunicación y creación de sentido—-, se eligió enmarcar este análisis

\footnotetext{
${ }^{6}$ Rovira (2018) establece que la difusión de este hashtag, originado en 2016 en Paraguay, cobró especial significado en México, durante 2017, tras el feminicidio de Lesvy Berlin, estudiante de la Universidad Nacional Autónoma de México y cuyo caso ocurrió en las instalaciones de dicha institución.
} 
a partir de la perspectiva de la espiritualidad, como se explica a continuación, una espiritualidad cristiana.

Desde la década de 1990, la espiritualidad se convirtió en una cuestión importante para la sociología de la religión. Diferentes aproximaciones han permitido situar en el campo religioso un conjunto de prácticas y sentidos sobre lo trascendente, en paralelo o de manera independiente a las religiones institucionalizadas, que permiten a sus practicantes una vivencia auténtica y personal de lo sagrado.

A grandes rasgos, la espiritualidad responde a dos modalidades: cristiana y postcristiana (Houtman y Aupers, 2007). En las primeras décadas del siglo XXI, el estudio de ésta se ha articulado, sobre todo, alrededor de lo que Houtman y Aupers (2007) denominan una espiritualidad postcristiana, la cual toma forma en diversas aproximaciones como: la espiritualidad del self, alternativa, para la vida, de la vida subjetiva y reflexiva, y las espiritualidades holísticas (Frigerio, 2016).

Sin embargo, para los fines de este artículo conviene tomar una posición analítica a partir de lo que se ha denominado una espiritualidad cristiana, la cual se caracteriza por ser teísta, por lo que "todavía se basa en la experiencia de lo sagrado como trascendente, es decir, como situado más allá del mundo o del cosmos" (Houtman, Heelas y Achterberg, 2012, p. 31 en Frigerio, 2016, p. 216). Como se mostrará más adelante, las madres de víctimas de feminicidio viven una espiritualidad de este tipo, la creencia en un ser omnipotente, que toma forma en un Dios cristiano, y que les permite resignificar tanto el feminicidio de sus hijas como el acceso a la justicia que exigen a raíz de éste.

La edad y el nivel socioeconómico son elementos importantes para reflexionar sobre la distancia que toman estas mujeres de una oferta espiritual postcristiana. En México es relativamente reciente la expansión de las prácticas que articulan esta espiritualidad, las cuales generalmente se ofertan con lógicas de consumo que limitan su acceso. Asimismo, debido a que es el feminicidio de sus hijas lo que las conecta con las matrices de sentido religioso que aprendieron en otras etapas de su vida, no acostumbran prácticas de religiosidad o mística popular con sus 
respectivos vínculos comunitarios. De acuerdo con Alejandro Frigerio la espiritualidad cristiana:

[...] se diferencia de la práctica usual dentro de [las] iglesias por prestarle más atención a las experiencias internas de los individuos [...] Su énfasis en lo individual es principalmente en atención a la experiencia religiosa, y no como fuente de la autoridad religiosa, que sigue estando localizada externamente, en la institución (2016, p. 226).

Es decir, mientras un sistema de creencias limita el significado de lo sagrado dentro de los tiempos y los calendarios de redención, la espiritualidad [cristiana] se relaciona con la vivencia interna de un sistema religioso (Pace, 2011) pero también, en casos como éste, con una distancia de sus instituciones y autoridades religiosas. Enzo Pace (2011) construyó un gradiente de la espiritualidad que "mide los diversos niveles de oportunidades individuales para manipular el significado que se atribuye a un conjunto de símbolos y prácticas religiosas” (p. 24). A la izquierda, se ubican las prácticas espirituales que se ajustan a un patrón de creencias definido por una religión, mientras que a la derecha están las prácticas que marcan una distancia máxima relativa con un sistema de creencias establecido (Pace, 2011).

En el caso de las madres de víctimas de feminicidio se identificó que es principalmente por medio de prácticas espirituales como la conversación interna y la oración que resignifican la violencia feminicida. En ellas aparecen matrices de sentido relacionadas con la vida después de la muerte, el sufrimiento, la justicia, el rol de madre; las cuales fueron aprendidas en las instituciones religiosas en otras etapas de su vida, pero que ahora cumplen un fin que se sitúa en el terreno individual, por lo que auxilian en la salud mental abriendo una vía para la vivencia subjetiva del duelo. En el gradiente de Pace (2011), estas prácticas se ubican a la izquierda, es decir, cerca de un sistema de creencias, por lo que forman parte de una espiritualidad cristiana.

De manera aislada también se identificaron las prácticas del pentecostalismo que son distintivas de las iglesias evangélicas pentecostales. Para Pace (2011) los avivamientos carismáticos que se viven en este tipo de iglesias representan un nuevo camino espiritual para interpretar el capital 
simbólico escrupulosamente guardado y cuidado por un sistema de creencias religiosas. Hay que destacar que este elemento es importante debido a que aun cuando las prácticas del pentecostalismo se experimentan en comunidades religiosas, priorizan una relación directa con Dios.

A continuación, se presenta el gradiente de la espiritualidad de Pace (2011) en el que es posible identificar las prácticas señaladas anteriormente, así como su cercanía o distancia con un sistema de creencias.

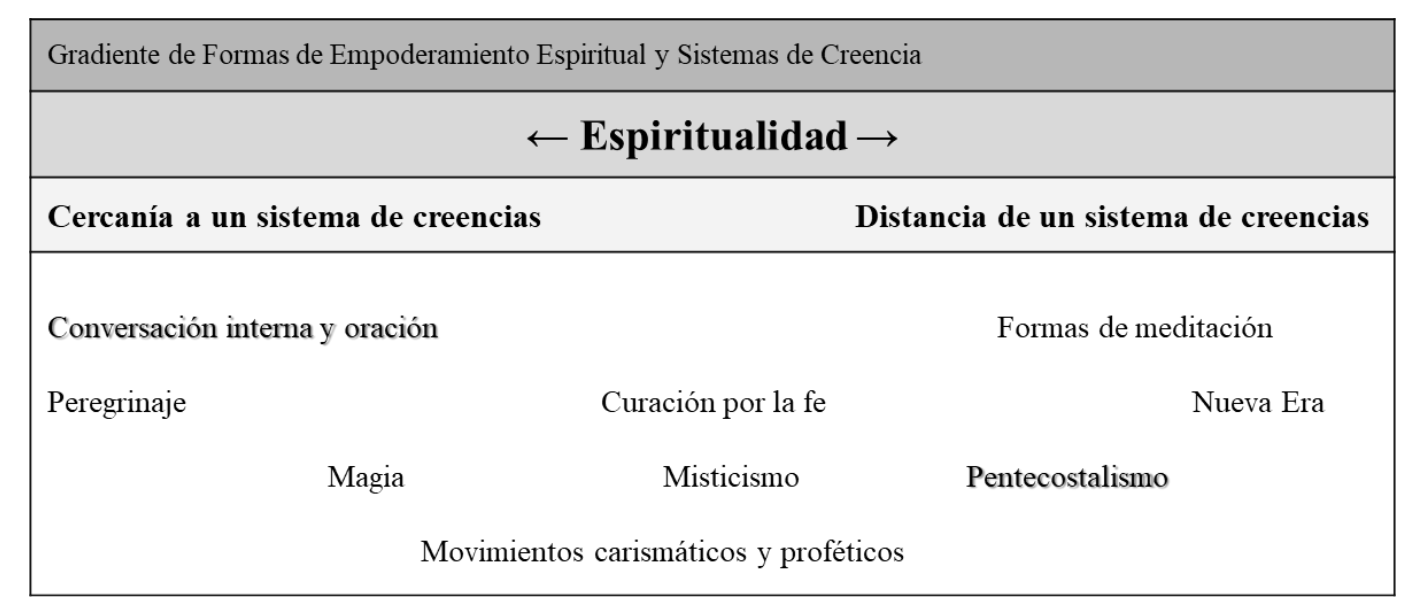

Figura 1. Elaboración propia con base en Pace (2011, p. 25).

\section{Coordenadas metodológicas}

Este artículo forma parte de una investigación más extensa realizada desde una perspectiva feminista de género ${ }^{7}$, y que se llevó a cabo entre agosto del 2016 y julio del $2018^{8}$, en la cual se describió la manera en que la violencia feminicida ocurrida entre 2010 y $2016^{9}$ es resignificada por las madres y familiares de víctimas de feminicidio; así como por sobrevivientes

\footnotetext{
${ }^{7}$ La perspectiva feminista de género se funda en procesos históricos y alternativas paradigmáticas a la dominación y opresión de género, edad, clase, etnia, religión, entre otras. Es una visión del mundo y una política que anhela "generar condiciones sociales que permitan a las mujeres vivir con bienestar y en libertad", así como impulsar la igualdad entre la sociedad (Lagarde, 2015, p.25).

${ }^{8}$ Véase Proo Méndez (2018).

${ }^{9}$ En el 2016 el gobierno mexicano utilizó el término "Defunciones Femeninas con Presunción de Homicidio (DFPH)" para referirse a los asesinatos de mujeres con características feminicidas, y que en ese año registró 2746 casos a nivel nacional, de los cuales el Estado de México presentaba 421, que lo colocaban como la entidad con mayor número de registros en números absolutos (ONU Mujeres, 2017).
} 
pertenecientes al Estado de México, entidad que en la última década ha ocupado los primeros lugares en la incidencia de este tipo de violencia ${ }^{10}$.

Se eligió el enfoque de investigación cualitativa, debido a que éste responde a interrogantes que tienen que ver con la profundidad — más no con la representatividad, como es el caso de los estudios cuantitativos - de la comprensión de la acción social y la construcción de significados a partir de la experiencia subjetiva de los individuos. En el presente artículo nos interesa poner en perspectiva el análisis de cinco testimonios pertenecientes a madres de víctimas, en los que expresaron de qué manera la espiritualidad se convierte en una estrategia con potencial político para sobrellevar el dolor, otorgar sentido y significado al feminicidio de sus hijas y, entonces, transformar en acción la denuncia contra la impunidad del Estado.

Strauss y Corbin (1990, en Vasilachis, 2006) señalan que este tipo de investigación se ocupa de la vida de las personas, historias, comportamientos, así como del funcionamiento organizacional de los movimientos sociales o de las relaciones interaccionales. De modo que, con el fin de retomar de manera amplia la descripción de las experiencias en torno a la violencia feminicida en madres de víctimas, se optó por la entrevista semiestructurada como técnica de investigación. Las entrevistas partieron de una guía que sirvió como pauta para cubrir las temáticas de interés, pero sin perder la oportunidad de realizar nuevos cuestionamientos en función de las narraciones.

Los ejes de dicha guía estuvieron encaminados a explorar aspectos de la experiencia personal, la interacción con actores institucionales y no institucionales, los significados de elementos de la vida cotidiana, así como la decisión o proceso de convertirse en activistas. Sin embargo, fue en las conversaciones sobre las estrategias en los procesos de búsqueda de justicia negociación con el dolor, la impunidad y la desaparición de mujeres— donde la espiritualidad emergió como un hallazgo importante de esta investigación, pues para las madres representó una estrategia para sobrellevar el duelo y otorgar un sentido a los feminicidios de sus hijas.

\footnotetext{
${ }^{10}$ La tipificación del feminicidio en el Código Penal del Estado de México se aprobó en marzo de 2011, antes de este tiempo los asesinatos de mujeres por razón de género eran catalogados como homicidios dolosos. La Alerta de Violencia de Género (AVG) fue decretada hasta el 2015.
} 
Para la interpretación de los datos se utilizó la Teoría Fundamentada, la cual parte de un enfoque interpretativo, basado principalmente en premisas del interaccionismo simbólico y la fenomenología sociológica, que destaca "[...] la capacidad de los actores de dar significado a diferentes situaciones sociales y de actuar, no sólo 'reaccionar', en consecuencia” (Castro, 2000, p. 27). En este sentido, una de las etapas que demandó el análisis de los datos fue una codificación abierta, la cual consiste en clasificar objetos para después ser agrupados en otros que desemboquen en categorías (Strauss y Corbin, 2002,).

Una de las categorías refería a las "Estrategias en los procesos de búsqueda de justicia: cómo lidiar con el dolor, la impunidad y la desaparición de mujeres" y en las que se destacó la espiritualidad como elemento clave para dar sentido a la búsqueda de justicia y como soporte al proceso de duelo de las entrevistadas. Aunado a ello, fue por medio del diario analítico que se descubrieron otros hallazgos sobre cómo se construye el significado de la violencia feminicida y la manera en la que éste incide no sólo en sus acciones, sino también en su actitud natural ${ }^{11} \mathrm{y}$ mundo de vida cotidiana (Proo, 2018).

\section{¿Quiénes son las madres víctimas de la violencia feminicida?}

Las mujeres que narraron su experiencia para esta investigación no sólo comparten en común el feminicidio de sus hijas — sucedidos todos en el Estado de México entre 2010 y 2016 —, sino también la exigencia de justicia y una toma de conciencia acerca del fenómeno, que las llevó a convertirse en activistas y acompañantes de otras denunciantes de violencia de género.

Todas manifiestan que su religión de origen es la católica, aunque en uno de los casos se realizó una conversión al cristianismo pentecostal y en otro una transición hacia una identificación sin religión. Sin embargo, sus testimonios coincidieron en una construcción de sentido que apunta a la creencia en una "justicia divina o celestial", que coadyuvó a contrarrestar su dolor y continuar con la exigencia de acceso a la justicia. A continuación, se describen puntualmente

\footnotetext{
${ }^{11}$ La actitud natural se define como aquella "[...] con la que funcionamos cotidianamente, y que nos permite entrar en contacto 'con la realidad' espontáneamente [...] se caracteriza por dar por sentadas el conjunto de cosas que me rodean y que definen y constituyen mi mundo cotidiano” (Castro, 2010, p. 111).
} 
los casos de las cinco madres, para quienes la espiritualidad constituyó una estrategia para resignificar la violencia feminicida de la que fueron víctimas sus hijas ${ }^{12}$.

\begin{tabular}{|c|c|c|c|c|c|}
\hline Nombre & $\begin{array}{c}\text { Año de } \\
\text { nacimiento } \\
\text { entrevistada }\end{array}$ & Religión & $\begin{array}{c}\text { Edad de } \\
\text { la víctima }\end{array}$ & $\begin{array}{l}\text { Lugar y fecha } \\
\text { del feminicidio }\end{array}$ & $\begin{array}{l}\text { Proceso judicial } \\
\text { del agresor }\end{array}$ \\
\hline Ana & 1971 & Católica & 14 & Ecatepec, 2014 & $\begin{array}{l}\text { Sin sospechoso } \\
\text { (s) }\end{array}$ \\
\hline Daniela & 1962 & Evangélica & 21 & $\begin{array}{c}\text { Atizapán de } \\
\text { Zaragoza, } 2011\end{array}$ & $\begin{array}{l}\text { Feminicida en } \\
\text { prisión: sentencia } \\
\text { de } 27 \text { años }\end{array}$ \\
\hline Lidia & 1980 & $\begin{array}{l}\text { Sin religión, } \\
\text { pero con } \\
\text { creencias }^{13}\end{array}$ & 16 & $\begin{array}{c}\text { Nicolás } \\
\text { Romero, } 2014\end{array}$ & $\begin{array}{l}\text { Feminicida en } \\
\text { prisión: sentencia } \\
\text { de } 66 \text { años }\end{array}$ \\
\hline Lourdes & 1973 & Católica & 17 & Ecatepec, 2016 & $\begin{array}{l}\text { Feminicida en } \\
\text { prisión: sentencia } \\
\text { de } 5 \text { años }\end{array}$ \\
\hline Lucía & 1952 & Católica & 29 & $\begin{array}{c}\text { Chimalhuacán, } \\
2010\end{array}$ & $\begin{array}{l}\text { Feminicida en } \\
\text { proceso jurídico, } \\
\text { sin sentencia }\end{array}$ \\
\hline
\end{tabular}

Tabla 1. Algunas características de las madres de víctimas de feminicidio entrevistadas.

Ana es habitante de Tecámac, Estado de México. Antes del feminicidio de su hija, se dedicaba a impartir cursos de superación personal; en la actualidad ofrece pláticas en escuelas de educación básica sobre la trata de personas y estrategias de seguridad digital. Su hija, que entonces tenía 14 años, desapareció en septiembre de 2013 en el municipio de Ecatepec; cinco meses después, autoridades mexiquenses hallaron restos de su cuerpo en un canal de aguas residuales. Hasta el momento de la entrevista, se desconocía al o los agresores.

Daniela — quien ahora preside una fundación encargada de brindar asesoramiento y acompañamiento a madres y padres de víctimas de desaparición en el Estado de México- entre 2011 y 2013 se dedicó a buscar a su hija desaparecida en el municipio de Atizapán de Zaragoza.

\footnotetext{
${ }^{12}$ En todos los casos se usaron nombres ficticios con el objetivo de salvaguardar la identidad y seguridad de las mujeres entrevistadas, puesto que algunas de ellas aún se encuentran en litigios o en búsqueda de justicia para sus casos.

${ }^{13}$ Carlos Mora Duro (2017) define a la población sin religión "como un conjunto de personas que manifiesta una desafiliación respecto a una o varias de las tradiciones del campo religioso, sin que esta desafiliación inicial corresponda intrínsecamente con una prescindencia absoluta de creencias y de prácticas de carácter religioso o espiritual" (p. 162).
} 
Ese último año, la encontró gracias a los registros de los entierros de la fosa común de Pachuca, Hidalgo. El cuerpo de su hija presentaba signos de violencia física y sexual. Luego de seis años de litigios, se identificó al agresor: la expareja sentimental de su hija. Éste fue detenido y acusado de homicidio doloso, a pesar de reunir los criterios de clasificación de un feminicidio; sin embargo, en aquel entonces, este crimen no estaba tipificado en el estado hidalguense. El agresor enfrenta una condena de 27 años de prisión.

En el 2014, Lidia vivía en el municipio de Nicolás Romero, donde se desempeñaba como trabajadora en una lavandería. Luego del feminicidio de su hija menor, sucedido ese mismo año, se dedicó al trabajo doméstico y al activismo. La víctima tenía entonces 16 años y se encontraba embarazada de su expareja y agresor, quién le hacía reclamos por haber iniciado una relación sentimental con otra persona. El feminicida fue detenido, se declaró culpable y enfrenta una condena de 66 años de prisión. Al momento de la entrevista, éste había interpuesto una apelación en su proceso jurídico, con el argumento de que fue obligado por las autoridades que lo interrogaron a declararse responsable del feminicidio.

Lourdes, quien en la actualidad se dedica al activismo y al trabajo doméstico, encontró en 2016 el cuerpo de su hija de 17 años en el baño de la casa donde vivían, la víctima presentaba signos de violencia física y sexual. En otra de las habitaciones, estaba también el cuerpo de su hijo menor de 12 años, quien había sido asfixiado. En el 2017 se halló al culpable de ambas muertes, mismo que enfrenta una condena en prisión de cinco años por ser juzgado como menor de edad.

Lucía es una de las activistas más visibles en la lucha contra la violencia feminicida en México. El feminicidio de su hija, ocurrido en 2010, fue el primer caso en su tipo atraído por la Suprema Corte de Justicia de la Nación (SCJN), instancia que en 2015 determinó que toda muerte violenta de una mujer ocurrida en este país debía investigarse con perspectiva de género. El cuerpo de la hija de Lucía fue hallado en su domicilio con muestras de asfixia y violencia física. Al principio de la investigación, su muerte fue catalogada por las autoridades mexiquenses como suicidio, sin embargo, luego de cinco años de exigencias por parte de Lucía y diversas ONG, el caso se reclasificó como feminicidio. El feminicida y expareja de la hija de Lucía, fue 
aprehendido en el 2016, pero hasta julio de 2019 seguía bajo proceso penal, sin que se le dictara sentencia.

\section{Matrices de sentido religioso para la espiritualidad y la resignificación de la violencia feminicida}

Para las madres, el feminicidio de sus hijas representa una ruptura emocional y de sentido trascendental, por lo que construyen marcos de significación que contribuyen a su bienestar subjetivo. En sus relatos fueron recurrentes los discursos en los que recuerdan haber sentido escalofríos, "corazonadas", o un aviso de su "sexto sentido" que les anticipó que sus hijas se encontraban en situaciones de peligro. El interaccionismo simbólico interpreta las operaciones y procesos psíquicos de los actores sociales, desde la funcionalidad que cumplen para su conducta (Joas, 1991). Es decir, dichos procesos se convirtieron en un hecho significativo para ellas, que les permitió aminorar el dolor de la pérdida de las víctimas.

Los presentimientos de las madres de víctimas de feminicidio también corresponden con las representaciones de la maternidad en los discursos religiosos — las cuales intervienen en las maneras como subjetivamente se vive este rol- ya que es a las madres a quienes se les atribuye una carga simbólica de dolor, sufrimiento y sumisión frente a diversas vicisitudes.

Aun cuando las prácticas religiosas y espirituales no formaban parte de su vida cotidiana, se ven en la necesidad de "buscar a Dios", es decir, de crear un vínculo de conexión con lo sagrado para entender su realidad inmediata y el sentido de su vida. Sin embargo, la eficacia simbólica (Durkheim, 1982) de recurrir de esta manera a una divinidad - que toma forma en un Dios cristiano - no pasa por la ortodoxia religiosa, ni por las prácticas y lazos comunitarios que éstas posibilitan, sino que, más bien, se gestiona desde la experiencia, es decir, desde la individualización de las creencias.

La oración y la conversación interna fueron las principales prácticas espirituales identificadas en las madres de víctimas de feminicidio, en ellas se retoman matrices de sentido religioso relacionadas con la vida después de la muerte, el sufrimiento, la justicia y el rol de género 
asociado a la maternidad. El relato de Ana que se presenta a continuación permite revelar de qué manera estas prácticas le permitieron resignificar lo sucedido con su hija.

Le dije: "vamos, Señor, permíteme, aunque sea saber de mi hija muerta, así como a la virgen le diste la oportunidad de secar la sangre de su hijo, de tu hijo". A la semana yo sentí que me iba a volver loca por no saber nada de mi hija. Entonces me arrodillé y fue cuando le dije a Dios: "permíteme tener a mi hija en mis brazos, de la forma que quieras entrégamela, así como le permitiste a María tener a Jesús en sus brazos muerto, dame la oportunidad de tener a la mía”. Fue como sacar todo el dolor que tenía en ese momento. Poco después me llamaron y me dijeron: "señora necesitamos verla" (fue cuando me informaron que habían encontrado partes del cuerpo de mi hija)" [...] Después me quedé pensando en la Virgen María, madre de Dios. Ella siendo la madre de Dios, estando en contacto con Dios padre, lo que tuvo que pasar con su hijo — un ser supremo, poderoso — pudo haber evitado la muerte de su hijo y tanto sufrimiento, ¿no? Entonces, ¿quiénes somos nosotros para pedir que nos entreguen a nuestros hijos vivos? (Ana, madre de víctima de feminicidio, entrevista personal).

En la interpretación que Ana hace sobre el sufrimiento de la madre de Jesús, encarnado en la virgen María, interviene una red de significados previos que ella había aprehendido de su interacción con otras personas de la religión católica, como su mamá. Es relevante dicha lectura como mecanismo para generar un sentimiento de calma ante la desesperación y otro de esperanza ante la incertidumbre por no encontrar con vida a su hija.

Lo dicho por Ana también revela que, si bien, en el caso de algunas madres de víctimas su faceta como activistas o acompañantes en situaciones similares a la suya las lleva a cuestionar en gran medida la herencia patriarcal de las religiones cristianas, no sucede lo mismo con su rol de género como madres, el cual, en medio de un acontecimiento como el feminicidio de sus hijas, resignifican a partir de matrices de sentido religioso.

La violencia feminicida, entre otras variantes, se caracteriza por la crueldad y saña con la que son asesinadas las mujeres. Por ello, en algunos casos, la oración y la conversación interna a 
partir de matrices de sentido religioso también se convierten en estrategias importantes para afrontar el momento en el que a las madres les son entregadas, únicamente, partes del cuerpo de las víctimas.

No está completo su cuerpo [el de la víctima], me faltan piernas, me faltan brazos, manos, pero creo que sí es ella. Para mí es muy gratificante $[\ldots]$ bueno, de cierta forma. Vas a decir "qué loca señora”, ¿no? [...] Yo sobreviví a esto pensando, "señor, tú permite que su cuerpo, tenga que pasar lo que tenga que pasar, pero cuida su alma que pertenece a ti, no permitas que sufra de cierta forma". Entonces para mí es importante saber que Dios tiene su alma y que ella ya tiene el privilegio de estar con él (Ana, madre de víctima de feminicidio, entrevista personal).

La función de la conversación interna como una práctica espiritual también es observable en quienes se consideran sin religión, como sucede con Lidia. En su caso la creencia en Dios, un ser superior y poderoso, le ayuda a sobrellevar el dolor y ha influido en la decisión de no atentar en contra de su propia vida ${ }^{14}$. Esta creencia, amparada en discursos bíblicos que pone en duda, le provee un sentimiento de esperanza acerca de volver a ver a su hija en un plano trascendental y a su vez le ayuda a enfrentar el sufrimiento de no ver a la víctima como parte de su mundo de vida cotidiano.

[...] si yo me suicido o hago algo en contra de mi persona, no voy a ver a mi hija, porque si algo dice la Biblia — te digo que quién sabe, todavía estoy en duda—, es que solamente Dios sabe en qué momento nos toca (morir) y cómo vamos a ver a nuestros seres queridos que ya se fueron. Pienso: "bueno, vamos a esperar a ver hasta dónde y hasta cuándo puedo verla, ¿no?”, aunque, te soy honesta, ganas y valor no me han faltado. Pero digo, "bueno, vamos a ver si realmente es lo que dice la Biblia, a ver si es cierto" (Lidia, madre de víctima de feminicidio, entrevista personal).

\footnotetext{
${ }^{14}$ Después del encuentro con la madre entrevistada, se le ofrecieron números de contactos de médicos especialistas para tratar el tema de intención de suicidio. Se consideró la obligación ética de las investigadoras para aportar opciones de acompañamiento o terapia psicológica a las personas que comparten testimonios de este tipo de experiencias sensibles.
} 
De los cinco casos que se presentan, la mediación de los vínculos comunitarios sólo fue observable en el caso de Daniela quien vivió un cambio de religión: de la católica a la cristiana evangélica. En las últimas décadas, el panorama religioso en México se ha distinguido por una tendencia que indica el paulatino descenso en el número de católicos, así como el incremento en el número de personas adscritas a las iglesias evangélicas. Dos características de estas denominaciones religiosas se pueden identificar en el discurso de Daniela: el apoyo de una comunidad religiosa y los rituales carismáticos típicos del pentecostalismo, en los que el creyente genera una relación directa con Dios, sin intermediarios, a través del cuerpo y del lenguaje.

Mi familia es muy católica y cuando ellos decidieron hacer una misa para mi hija, yo fui con el padre para que me dijera unas palabras de aliento, de consuelo, y lo único que me dijo fue: “¡Ay, mija! ¡Lástima que vives en México! [...] Aquí no pasa nada, no hay resultados, no hay nada, ¡Que Dios te bendiga!”. En vez de motivarme, pues me bajó más el ánimo. Mi cuñada hizo fotos, hizo misas en La Villa, para mi hija, pero le cobraban dos mil pesos solamente por nombrarla. La iglesia católica me había defraudado. Me acerqué al cristianismo, ellos sin ningún interés oraban por mi hija. Me hacían sentir que no estaba sola. Ahí encontré una familia para descansar un poco mi dolor y hacerme sentir bien. Ahí conocí a Dios, también. Gracias a mi hija conocí a Dios. Y aquí lo tengo ahorita presente en todo momento (Daniela, madre de víctima de feminicidio, entrevista personal).

El relato de Daniela destaca la centralidad de la oración como una práctica que le permitió descansar un poco su dolor y sentirse bien, así como otorgar un sentido al feminicidio de su hija, al considerar que, aun cuando no entiende la razón por la que sucedió, este acontecimiento trágico sirvió para acercarse y conocer a Dios.

Las prácticas de espiritualidad cristiana que se han presentado cumplen el mismo propósito que Ramírez Morales (2019) ha identificado por medio del estudio de espiritualidades postcristianas como los círculos de mujeres: sanar las heridas provocadas por las agresiones patriarcales, en 
este caso marcadas por la violencia feminicida que aniquila la existencia de las víctimas y menoscaba las de sus sobrevivientes.

Para las madres de víctimas de feminicidio pensar en un mundo trascendental en el que se encuentra un Dios, que han conocido gracias a alguna religión de raíces cristianas como la católica o la evangélica, les brinda consuelo y les ofrece satisfacción a sus demandas de sentido, lo cual interviene de manera positiva en su salud mental y su bienestar emocional, generando otras condiciones para la vivencia subjetiva del duelo. Además, las ayuda a significar sus acciones como activistas o mujeres que deciden emprender una lucha contra el sistema jurídico, para que les sea garantizado el acceso a la justicia respecto a los casos que les atañen o a los de otras mujeres a las que buscan ayudar.

\section{Resignificar la (in) justicia: la ley divina o ley de Dios}

Uno de los aspectos que fortalece la impunidad en los casos de violencia feminicida en México, es la dificultad en el acceso a la justicia para las víctimas colaterales del feminicidio, en este caso, las madres. La Comisión Nacional de Derechos Humanos (CNDH) dio a conocer en 2016 que, de 1662 delitos de este tipo cometidos ese año, 947 fueron consignados y de éstos, sólo el 10\% logró la detención del presunto culpable (CNDH, 2018).

Sobre dicho panorama, se identificó en las madres de víctimas de feminicidio entrevistadas un proceso de resignificación de la justicia en el que, ante la falta de ésta por parte de las autoridades judiciales para atender sus casos con debida diligencia, apelan a una "justicia divina o celestial", que consideran como infalible. Ello revela el potencial político y de resistencia de la espiritualidad cristiana que aquí se analiza.

Por medio de su trabajo con un colectivo de personas trans, uno femenino afrodescendiente y una fundación que apoya el desarrollo integral de mujeres en situaciones de vulnerabilidad, Mónica Maher (2015) establece que aun cuando en el imaginario hegemónico histórico y actual, la espiritualidad se considera sumamente privada y apolítica, en realidad, es profundamente 
pública y política. Ésta cuenta con una gran posibilidad para el bien-estar individual-colectivo de mujeres viviendo múltiples marginalizaciones.

Esto mismo es observable en las madres de víctimas de la violencia feminicida, quienes por medio de la resignificación de la justicia "ponen en evidencia el papel clave de las espiritualidades en los procesos sociales de lamento, sobrevivencia, resistencia [...] aun cuando nacen de religiones que son en sí fuentes de exclusión, condenación y discriminación” (Maher, 2015, p.11).

La "justicia divina" se deriva de la creencia en la existencia de un Dios que más allá del plano terrenal da a cada uno lo que le corresponde de acuerdo con la manera como condujo su vida. Los buenos actos se premian, mientras que los malos se castigan. En el caso de las madres de víctimas de violencia feminicida esta representación se traduce en la esperanza de que los agresores de sus hijas sean identificados y sentenciados, lo cual tiene escasas o nulas posibilidades de suceder.

A continuación, se presentan los testimonios de cuatro de las madres entrevistadas en los que es posible identificar que, si bien, la resignificación de la justicia está mediada por la invocación a una divinidad, cumple un propósito para el aquí y el ahora, tal como sucede con cualquier práctica espiritual.

Cuando le dije [al agresor] que ya la había matado, que debería de sentirse contento, — después de todas las maldiciones que le había lanzado- le dije, "pero una cosa sí te digo, te salvarás de la ley de los hombres, pero de la ley de Dios nunca te vas a salvar". Él me contestó, “eso ya lo sé”. Le respondí: “qué bueno que lo sepas, porque ni siquiera te imaginas lo que acabas de hacer y terrible cosa es caer en manos de mi divino y Dios va a hacer justicia" [...] Independientemente de que el asesino de mi hija esté preso, yo a mi hija nunca la voy a volver a ver. La reparación del daño no existe. No hay. No hay porque nunca voy a volver a ver a mi hija con vida y es un dolor que siempre va a estar 
allí. Solamente la fuerza que Dios me da es lo que me ha ayudado a sobrellevar este dolor (Lucía, madre de víctima de feminicidio, entrevista personal).

Para mí hay dos tipos de justicia. Tanto la religiosa, que sé que de esa no hay escapatoria, y la legal, la del juicio de aquí, en la tierra. [...] A mí también me darían ganas de despellejar poquito a poquito a quien le hizo eso a mi hija, pero entonces ahí viene lo religioso. Si sacas y desfogas te convertirías en alguien peor que ellos y, perder mi lugar en el cielo por una persona que ya está perdida [...] darle esa especie de satisfacción de que ella se merezca el cielo y yo no [...] no, mejor lo perdono, un día Dios se va a encargar de la justicia (Ana, madre de víctima de feminicidio, entrevista personal).

Yo digo que la justicia es encontrar a los verdaderos asesinos, que paguen donde tienen que pagar, ya sea en la cárcel o ya sea con la justicia divina, como muchas veces se dice, porque a veces la justicia de las autoridades no llega, pero la justicia de Dios tarde o temprano llega. Eso sería la justicia: que paguen donde tengan que pagar (Lourdes, madre de víctima de feminicidio, entrevista personal).

Si no llegara la justicia en lo que yo estoy viva, porque yo creo que nadie va a seguir el caso de mi hija, si yo llego a morir, allá arriba se va a hacer justicia. Pero sí duele saber que no se te haga justicia como ser humano. Yo creo que por mucho que tengas fe, por mucho que creas en Dios, por mucho que seas buena persona y trates de ser positiva, sí ansías esa parte de la justicia legal (Ana, madre de víctima de feminicidio, entrevista personal).

Las madres de víctimas de feminicidio utilizan la creencia religiosa sobre la existencia de la "ley divina" como mecanismo que les genera fe o esperanza para que los agresores, independientemente de si son detenidos por las autoridades o no, paguen por los feminicidios de sus hijas en un mundo trascendental. En paralelo, el proceso de resignificación a partir de dicha creencia revela la ineficacia e insuficiencia del sistema de justicia mexicano, lo cual es alarmante ante el crecimiento y expansión de la violencia feminicida en el país. 
Lagarde (2015) afirma que la religión genera la esperanza para contrarrestar la evidente injusticia y la opresión que viven cotidianamente los seres humanos y en particular las mujeres. No obstante, las madres de víctimas de feminicidio no se desaniman por completo ante las fallas en el sistema de justicia, por el contrario, afirman que su creencia en Dios y las prácticas de la espiritualidad cristiana que ya se han enunciado les proveen de sentido para continuar con mayor ímpetu la exigencia de sus demandas y de otros casos similares.

Éste es un hallazgo importante en tanto revela cómo la búsqueda de justicia en instituciones seculares también es impulsada desde marcos de sentido religioso. Asimismo, se evidencia de qué manera convergen estructuras de sentido de dos campos que se consideran opuestos en una agenda política que intenta erradicar las desigualdades de género.

\title{
Reflexiones finales:
}

\section{La experiencia de la violencia feminicida en torno a las prácticas de sentido y bienestar subjetivo desde la espiritualidad}

\begin{abstract}
A lo largo de estas páginas se describió la importancia que tiene el análisis microsociológico de un fenómeno que apremia a la sociedad mexicana desde hace más de dos décadas y que atenta en contra de la vida de las niñas y las mujeres: la violencia feminicida. Constituido como un mecanismo letal del orden patriarcal, esta problemática se conforma de varias aristas desde las cuales puede analizarse y cuestionarse, una de ellas es por medio de la religión y la espiritualidad que proveen estructuras de sentido para significar y enfrentar el feminicidio.
\end{abstract}

Además de abordar el contexto que guarda este tipo de violencia bajo el movimiento feminista que ha luchado por erradicarla, este artículo abre una senda de reflexión hacia las prácticas que, desde la espiritualidad cristiana, generan sentido y contribuyen al bienestar subjetivo en madres de víctimas de violencia feminicida. La creación de un vínculo con lo sagrado genera la individualización de las creencias y ésta funciona como estrategia para sobrellevar el dolor de la ausencia y pérdida de sus hijas, víctimas de feminicidio. 
A partir de marcos de sentido religioso, destacaron también la oración y la conversación interna como prácticas de la espiritualidad cristiana que permiten resignificar este fenómeno y reforzar la creencia en una "ley divina" que contribuye a hacer frente a la búsqueda de acceso a la justicia en el contexto mexicano, donde casos de este tipo tienden a quedar irresolutos. La manera de recurrir a la divinidad, sin una institución religiosa de por medio, hace que las madres de víctimas de feminicidio apelen a la espiritualidad para otorgar un sentido al feminicidio de sus hijas y encaminar sus acciones en virtud de ser activistas.

\section{Referencias bibliográficas}

Álvarez, Lucía. (2020). El movimiento feminista en México en el siglo xxI: juventud, radicalidad y violencia. Revista Mexicana de Ciencias Políticas y Sociales, 65(240), 147-175. doi: http://dx.doi.org/10.22201/fcpys.2448492xe.2020.240.76388

Antillón, Ximena y González, Mauricio. (2018). Políticas del duelo: entre lo psíquico y lo social. Argumentos, $\quad$ (87), $\quad 37-54 . \quad$ Recuperado de https://argumentos.xoc.uam.mx/index.php/argumentos/article/view/1030

Atencio, Graciela. (8 de marzo 2011). Feminicidio-femicidio: un paradigma para el análisis de la violencia de género. Feminicidio.net. Recuperado de https://feminicidio.net/feminicidio-femicidio-un-paradigma-para-el-analisis-de-laviolencia-de-genero/

Bárcenas Barajas, Karina. (2020). Bajo un mismo cielo: las iglesias para la diversidad sexual y de género en un campo religioso conservador. México: Instituto de Investigaciones Sociales, Universidad Nacional Autónoma de México.

Bárcenas Barajas, Karina. (2021). A manera de introducción: problematizar el derecho a decidir sobre el propio cuerpo. En Karina Bárcenas (Coord.), Género y sexualidad en disputa. Desigualdades en el derecho a decidir sobre el propio cuerpo desde el campo médico 
(pp.7-33). Instituto de Investigaciones Sociales, Universidad Nacional Autónoma de México.

Castro, Roberto. (2000). La vida en la adversidad: el significado de la salud y la reproducción en la pobreza. Morelos: Universidad Nacional Autónoma de México, Centro Regional de Investigaciones Multidisciplinarias.

Castro, Roberto. (2010). Teoría social y salud. México y Buenos Aires: El Lugar Editorial, Centro Regional de Investigaciones Multidisciplinarias.

Comisión Nacional de Derechos Humanos (CNDH). (2018). Diagnóstico nacional de acceso a la justicia y violencia feminicida 2016. México: UAM-I.

De la Torre, Renée. (2013). La Religiosidad Popular. Encrucijada de las nuevas formas de la religiosidad contemporánea y la tradición (el caso de México). Ponto Urbe. Revista do núcleo de antropologia urbana da USP, (12). doi: https://doi.org/10.4000/pontourbe.581

Durkheim, Émile. (1982). Las formas elementales de la vida religiosa. Madrid: Akal.

Espino, Saúl. (2019). Feminismo católico en México: la historia del CIDHAL y sus redes transnacionales (c. 1960-1990). (Tesis de Doctorado). El Colegio de México, México. Recuperada de https://colmex.userservices.exlibrisgroup.com/view/delivery/52COLMEX INST/1292 972660002716?language $=$ es

Frigerio, Alejandro. (2016). Epílogo. La ¿"nueva"? Espiritualidad: ontologia, epistemologia y sociologia de un concepto controvertido. Ciencias Sociales y Religión/Ciências Sociais e Religião, 18(24), 209-231. doi: https://doi.org/10.22456/1982-2650.67123 
hooks, bell (2017). El feminismo es para todo el mundo. Madrid: Traficantes de sueños. Recuperado de https://www.traficantes.net/sites/default/files/pdfs/TDS_map47_hooks_web.pdf

Houtman, Dick y Aupers, Stef. (2007). The Spiritual Turn and the Decline of Tradition: The Spread of Post-Christian Spirituality in 14 Western Countries, 1981-2000. Journal for the Scientific Study of Religion, 46(3), 305-320. doi: 10.1111/j.1468-5906.2007.00360.x

Joas, Hans. (1991). Interaccionismo simbólico. En Anthony Giddens y Jonathan Turner (Eds.), La teoría social hoy (pp.112-154). México: Alianza Editorial

Lagarde, Marcela. (2006). Del femicidio al feminicidio. Desde el jardín de Freud, (6), 216-225. Recuperado de https://revistas.unal.edu.co/index.php/jardin/article/view/8343

Lagarde, Marcela. (2008). Antropología, feminismo y política: violencia feminicida y derechos humanos de las mujeres. En Margaret Bullen y Carmen Diez (Comp.), Retos teóricos y nuevas prácticas (pp.209-240). España: Editores Ankulegi

Lagarde, Marcela. (2015). Los cautiverios de las mujeres: madres, esposas, monjas, putas, presas y locas. México: Siglo XXI Editores.

Maher, Mónica. (2015). Las espiritualidades diversas por los derechos colectivos: Activismo Sagrado en Quito. Fundación Museos de la Ciudad. Recuperado de http://www.igcuu.org/wp-content/uploads/2016/04/Fundacio\%CC\%81n-MDCPonencia-Espiritualidades-Diversas-por-los-Derechos-Colectivos-2015.pdf

Mazariegos, Hilda. (2019). Mujeres metodistas en León, Guanajuato-México: liderazgos en movimiento. Revista Cultura y Religión, 13(1), 24-44. Recuperado de https://www.revistaculturayreligion.cl/index.php/revistaculturayreligion/article/view/8 50 
Mora, Carlos. (2017). Entre la crítica, la autonomía y la indiferencia: la población sin religión en México. Estudos de religiao, 31(3), 157-178. doi: https://doi.org/10.15603/21761078/er.v31n3p157-178

Odgers, Olga y Olivas, Olga (Coords.). (2018). ¿Dejar las drogas con ayuda de Dios? Experiencias de internamiento en centros de rehabilitación fronterizos. Tijuana: El Colegio de la Frontera Norte

ONU Mujeres, Entidad de las Naciones Unidas para la Igualdad de Género y el Empoderamiento de las Mujeres, Secretaría de Gobernación, SEGOB e Inmujeres (2017). La violencia feminicida en México, aproximaciones y tendencias (1985-2016). México: ONU Mujeres

Ortega, Abeyamí y Miller, Toby. (2017). \#VivasNosQueremos. La crisis de violencia de género en México, ciudadanía, estereotipos y resistencias en la era neoliberal. En Carlos del Valle y Víctor Silva (Eds.), Crisis, Comunicación y Crítica Política (pp.230-260). Quito: Ediciones CIESPAL.

Pace, Enzo. (2011). Spirituality and Systems of Belief. En Giuseppe Giordan y William Swatos (Eds.), Religion, Spirituality and Everyday Practice (pp. 23-32). London: Springer

Proo Méndez, Eleane. (2018). La construcción del significado de la violencia feminicida: nueve casos de familiares de víctimas y sobrevivientes en el Estado de México. (Tesis de Maestría en Comunicación). Universidad Nacional Autónoma de México, México. Recuperada de http://132.248.9.195/ptd2018/septiembre/0780388/Index.html

Puentes, Yesica; Urrego, Sandra y Sánchez, Ricardo. (2015). Espiritualidad, religiosidad y enfermedad: una mirada desde mujeres con cáncer de mama. Avances en Psicología Latinoamericana, 33(3), 481-495. doi: http://dx.doi.org/10.12804/apl33.03.2015.08 
Radford, Jill y Diana Russell (Comps.). (2006). Feminicidio. La política del asesinato de las mujeres. México: Centro de Investigaciones Interdisciplinarias en Ciencias y Humanidades, Universidad Nacional Autónoma de México.

Ramírez Morales, María del Rosario. (2019). Espiritualidades femeninas: el caso de los círculos de mujeres. Encartes. Revista Digital Multimedia 2(3), 144-162. Recuperado de https://encartes.mx/espiritualidades-circulos-de-mujeres/

Rovira Sancho, Guiomar. (2018). El devenir feminista de la acción colectiva: las redes digitales y la política de prefiguración de las multitudes conectadas. Teknokultura, 15(2), 223240.

Salgado, Ana. (2014). Revisión de estudios empíricos sobre el impacto de la religión, religiosidad y espiritualidad como factores protectores. Propósitos y Representaciones. Revista de Psicología Educativa 2(1), 121-159. doi: http://dx.doi.org/10.20511/pyr2014.v2n1.55

Salles, Vania y Valenzuela, José. (1997). En muchos lugares y todos los días: vírgenes, santos y niños Dios: mística y religiosidad popular en Xochimilco. México: El Colegio de México.

Scott, Joan. (1996). El género: una categoría útil para el análisis histórico. En Marta Lamas (Comp.), El género: la construcción social de la diferencia sexual (pp. 265-302). México: PUEG, Miguel Ángel Porrúa

Secretaría de Gobernación (SEGOB). (2007). Ley General de Acceso de las Mujeres a Una Vida Libre de Violencia. Diario Oficial de la Federación. Recuperado de http://www.diputados.gob.mx/LeyesBiblio/pdf mov/Ley General de Acceso de las Mujeres_a_una_Vida_Libre_de_Violencia.pdf 
Strauss Anselm y Corbin, Juliet. (2002). Bases de la investigación cualitativa. Técnicas y procedimientos para desarrollar la teoría fundamentada. Colombia: Editorial Universidad de Antioquia.

Toniol, Rodrigo. (2015). Espiritualidade que faz bem. Pesquisas, políticas públicas e práticas clínicas pela promoção da espiritu alidade como saúde. Sociedad y Religión, 25(43), 110-143. Recuperado de https://www.redalyc.org/articulo.oa?id=387239046005

Valiente-Barroso, Carlos. (2013). Intersecciones entre espiritualidad/religiosidad y psicología: desde la filosofia hasta la neurociencia. Revista de Historia de la Psicología 34(4), 6788. Recuperado de https://www.actiweb.es/lumen/archivo4.pdf

Vasilachis de Gialdino, Irene. (Coord.) (2006). Estrategias de investigación cualitativa. Barcelona: Gedisa

Villalobos, Sandra. (2016). Igualdad y trabajo pastoral: La experiencia de las mujeres en los ministerios religiosos ordenados y consagrados en México. Revista Interdisciplinaria de Estudios de Género de El Colegio de México, 2(4), 76-102. doi: https://doi.org/10.24201/eg.v2i4.60

\section{Entrevistas}

Ana, entrevista personal, madre de víctima de feminicidio, Tecámac, Estado de México, 14 de diciembre de 2016.

Daniela, entrevista personal, madre víctima de feminicidio, Ciudad de México, México,17 de marzo 2017.

Lidia, entrevista personal, madre de víctima de feminicidio, Ecatepec, Estado de México, 8 de marzo de 2017. 
Lourdes, entrevista personal, madre de víctima de feminicidio, Ciudad de México, México, 12 de marzo de 2017.

Lucía, entrevista personal, madre de víctima de feminicidio, Ciudad de México, México, 19 de marzo de 2017.

\section{ELEANE PROO MÉNDEZ}

Estudiante de doctorado en la Facultad de Ciencias Políticas y Sociales de la Universidad Nacional Autónoma de México (UNAM), con orientación en Sociología; maestra en Comunicación por el posgrado de Ciencias Políticas y Sociales de la misma universidad y diplomada en Relaciones de Género por el Centro de Investigaciones y Estudios de Género (CIEG-UNAM). Cuenta con una estancia de investigación en el Instituto de Investigaciones Feministas de la Universidad Complutense de Madrid (UCM). Áreas de interés: violencia feminicida, teoría feminista, sociología del cuerpo y tecnologías de la reproducción.

\section{KARINA BÁRCENAS BARAJAS}

Doctora en Ciencias Sociales con especialidad en Antropología Social por el Centro de Investigaciones y Estudios Superiores en Antropología Social (CIESAS) Occidente. Se desempeña como investigadora en el Instituto de Investigaciones Sociales de la Universidad Nacional Autónoma de México (IIS-UNAM). Pertenece al Sistema Nacional de Investigadores, nivel I. Sus líneas de investigación son: 1) religión, diversidad sexual y cultura política; 2) identidades, género y movimientos sociales; 3) construcción social del género y la sexualidad. Entre sus publicaciones más recientes se encuentran:(2021). Género y sexualidad en disputa. Desigualdades en el derecho a decidir sobre el propio cuerpo desde el campo médico (Coord.). Instituto de Investigaciones Sociales, Universidad Nacional Autónoma de México. (2021). La violencia simbólica en el discurso sobre la "ideología de género": una perspectiva desde la dominación simbólica a través del pánico moral y la posverdad. Intersticios Sociales, (21), 125150. 